\title{
A FORMAÇÃO DO PROFISSIONAL DA SAÚDE NA PERSPECTIVA DA SEMIÓTICA
}

\section{THE VOCATIONAL TRAINING OF HEALTHCARE PROFESSIONALS IN THE PERSPECTIVE OF SEMIOTICS}

\author{
EUNiCE ALMEIDA DA SILVA * \\ ANDERSON VINÍ́CIUS ROMANINI **
}

RESUMO: Este ensaio apresenta uma proposta de referencial teórico para a formação do profissional da área da saúde baseado na filosofia pragmática de Charles Sanders Peirce, mais especificamente na classificação dos tipos de raciocínios, na concepção de diagrama e na descrição do processo mental como uma relação triádica entre signo, objeto e interpretante (semiose). Estudos revelam que a comunicação entre o profissional da saúde e a pessoa assistida tem sido estabelecida de maneira descontextualizada; decorrente, muitas vezes, da ênfase que esse profissional atribui a realização do procedimento técnico-científico e aos protocolos pré-determinados. Propomos: 1. uma análise do processo de comunicação entre o profissional da saúde e a pessoa que requer cuidados, entendido como um processo que se pauta na ação do signo, ou

* Docente da USP - Universidade de São Paulo. E-mail: eunice.almeida@usp.br.

** Docente da USP - Universidade de São Paulo. E-mail: vinicius.romanini@usp.br. 
semiose; 2. a elaboração de um plano de cuidado/tratamento como um processo projetivo diagramático que contempla múltiplas variáveis e que requer o auxílio dos raciocínios abdutivo, dedutivo e indutivo para realizar eficientemente seu propósito.

PALAVRAS-CHAVE: Comunicação. Formação do profissional de saúde. Semiose. Plano de cuidados. Semiótica.

ABSTRACT: This essay proposes a theoretical framework for the education and training of healthcare professionals based on Charles Sanders Peirce's pragmatic philosophy, more specifically, on his classification of the kinds of reasoning, his conception of diagram and his description of the mental process as a triadic relation among sign, object and interpretant (semiosis). Studies show that communication between health professionals and assisted people often happens in a decontextualized manner due to the emphasis that these professionals attribute to the accomplishment of scientific-technical procedures and predetermined protocols. Therefore, this essay proposes: 1 . An analysis of the process of communication between health professionals and people requiring care, which is understood as a process guided by the action of the sign, or semiosis; 2 . the elaboration of a care/ treatment plan as a projective diagrammatic process that includes multiple variables and requires the aid of abductive, deductive and inductive reasoning to efficiently accomplish its purpose.

KEYWORDS: Communication. Education and training of health professionals. Semiosis. Care planning. Semiotics. 


\section{Introdução}

Estudos revelam que a comunicação entre os profissionais da saúde, e deles com a pessoa assistida, realiza-se muitas vezes de maneira descontextualizada. 0 artigo "Parturiente e equipe obstétrica: a difícil arte da comunicação" (CARON; SILVA, 2002) mostra que a comunicação entre profissionais responsáveis pela assistência obstétrica e a mulher assistida tem um caráter de impessoalidade e de exercício de poder do profissional sobre a mulher parturiente. Um aspecto relevante constatado no estudo é a repressão de comportamentos tidos como indesejáveis no momento do parto, como gritar, chorar e se agitar.

Ao modelo de atendimento descontextualizado soma-se a aplicação de mecanismos hegemônicos de linguagem, tais como códigos técnico-científicos, que garantem a submissão das mulheres à rotina dos serviços de saúde e ao desconhecimento do funcionamento e controle do seu próprio corpo, alienando-a do processo de conhecimento e decisão sobre sua saúde. 0 Ministério da Saúde reconhece a necessidade de uma nova política pública para lidar com a saúde da mulher. Já em 1986, a VIII Conferência Nacional de Saúde enfatizava o direito à saúde e à livre expressão como dimensões integradas (BRASIL, 1986). Apesar disso, o documento "Parto, Aborto e puerpério: assistência humanizada à mulher" descreve assim $\mathrm{o}$ atendimento à saúde das mulheres:

[...] Gravidez, parto, aleitamento, menopausa e a sexualidade feminina foram regulados conforme as normas e procedimentos do modelo hegemônico, ou seja, gravidez e menopausa como eventos patológicos que devem sofrer intervenções médicas e tecnológicas; parto como evento médico e cirúrgico; aleitamento materno visando apenas à diminuição da 
mortalidade infantil; e a sexualidade feminina excluída das discussões pelos profissionais de saúde. (BRASIL, 2001).

A Política Nacional de Humanização da atenção e gestão no Sistema Único de Saúde - Humaniza SUS (BRASIL, 2004) - buscou a valorização dos diferentes sujeitos implicados no processo de produção da saúde: usuários, trabalhadores e gestores. A autonomia e o protagonismo dos sujeitos, a corresponsabilidade entre eles, o estabelecimento de vínculos solidários e a participação coletiva no processo de gestão são algumas condições necessárias para a implementação dessas políticas públicas. Entretanto, essas condições parecem se diluir quando se estabelece o processo de comunicação entre os profissionais da saúde e a mulher assistida; uma vez que tal processo se cristaliza em um ponto que faz sentido apenas aos profissionais dessa área, ou seja, o sentido técnico- científico.

Os resultados da pesquisa de Caron e Silva (2002) mantêm-se atuais, pois revelam o enorme desencontro entre as finalidades das políticas públicas, voltadas para a melhoria da saúde da população e o tipo de comunicação estabelecida entre os profissionais da saúde e a mulher assistida no momento do parto. De fato, o profissional de saúde exerce a sua prática dentro de um campo estreito de comunicação e informação, o que resulta na exclusão de possibilidades de narrativas da mulher e, consequentemente, na desconsideração desta enquanto um ser único, singular, cuja identidade é feita pela memória de sua própria história de vida.

A preocupação principal dos profissionais de saúde parece ser a de eliminar os sintomas produzidos pela doença ou mal-estar, por meio de uma terapêutica que só favorece o acesso a medicamentos e dispositivos que são comercializados. Isto dificulta a compreensão dos sintomas como traços que também representam a própria pessoa em sua singularidade e contexto. 
Algumas ferramentas da semiótica moderna ${ }^{1}$ poderiam contribuir para aproximar as finalidades das políticas públicas de melhoria do atendimento à saúde da mulher, com as práticas dos profissionais da saúde. Ancorada na fenomenologia e na lógica da representação, a semiótica estuda como são constituídos os fenômenos, o que esses significam e como se fazem representar por meio de diversas linguagens, revelando o papel do signo nos processos de comunicação.

Acreditamos que o entendimento de como um fenômeno é significado e representado poderia ajudar na concretização das políticas públicas voltadas à melhoria da qualidade do atendimento à saúde, garantindo a adesão ao tratamento por parte da pessoa assistida e, consequentemente, o restabelecimento de sua saúde.

\section{A filosofia semiótica de Peirce}

De acordo com a filosofia do lógico e matemático norte-americano Charles S. Peirce (1839-1914), o criador da semiótica moderna, fenômeno é tudo aquilo presente em uma mente, independente de ser ou não real. Os fenômenos são compostos por três categorias básicas, que se misturam continuamente para nos oferecer uma representação do real. Essas categorias podem ser possibilidades ou qualidades que ele chamou de primeiridades, reações concretas existentes de segundidades ou hábitos e padrões gerais de terceiridades.

Uma alucinação, por exemplo, é um fenômeno tanto

1 A tradicional semiótica médica remonta aos tratados de Galeno na Grécia Antiga, mas focava basicamente na identificação e interpretação dos sintomas. A semiótica moderna, principalmente a de matriz peirceana, é estudada como uma lógica geral que envolve a percepção dos fenômenos, a representação na linguagem e a comunicação social (MANETTI, 1993). 
quanto a batida da cabeça contra uma parede. 0 que os distingue são os aportes que eventualmente trazem aos nossos hábitos de conduta futura. Quando breve e eventual, uma alucinação tende a desaparecer sem deixar consequências marcantes na nossa maneira de agir no mundo, mas um choque contra a parede pode ter influências importantes na nossa conduta: tenderemos a prestar mais atenção para não trombar com paredes. Por outro lado, uma alucinação insistente, que resiste mesmo quando confrontada com relatos de outras pessoas, assume para quem alucina uma concretude que simula a existência e que, portanto, exige medidas igualmente concretas contra ela.

Embora a realidade seja, para Peirce, algo inteiramente independente de nossas capacidades cognitivas individuais, a representação social que fazemos dos fenômenos percebidos, por meio da comunicação, tende a garantir que nossas experiências individuais não são alucinações, e sim uma crença fundamentada sobre uma realidade que se impõe a todos da comunidade de maneira semelhante. Ou seja: os fenômenos da experiência compartilhada são a base de nosso conhecimento, que cresce no interior de uma comunidade de pessoas interessadas.

Peirce desenvolveu uma teoria dos signos em que o conhecimento lógico da realidade se fundamentava na comunicação. Por isso, considerou três doutrinas como essenciais para que a comunicação aconteça na direção do desenvolvimento e do aumento da informação. A primeira é a doutrina da generosidade, do envolvimento interessado apenas no conhecimento, da união das pessoas entorno de um propósito ou ideal futuro: o agapismo. A segunda é a doutrina da humildade intelectual, da admissão de que nenhum corpo de conhecimento é infalível, absoluto e completo: o falibilismo. A 
terceira doutrina é a de que a experiência tem sempre um elemento de acaso, de incontrolável, de imprevisível e que brota de nossa dimensão perceptiva individual, fazendo de cada um de nós indivíduos únicos no interior de uma comunidade de semelhantes: o tiquismo (BERGMAN, 2000).

Quando uma ou mais dessas doutrinas estão ausentes, distanciamo-nos da comunicação e assumimos posturas solipsistas, egoístas e prepotentes que nos desviam do caminho da busca do bem coletivo e nos criam ilusões de onisciência e onipotência. 0 método científico da maneira como Peirce o concebeu em seu pragmatismo, baseado num processo lógico que privilegia a fenomenologia da percepção, a experiência compartilhada e a comunicação, é exemplo de como uma comunidade interessada no conhecimento se mantém aberta a novas hipóteses, reconhecendo sua falibilidade, ao mesmo tempo que divide com seus pares e com os demais interessados os resultados de suas experiências e reflexões individuais.

Tendo esta breve exposição dos fundamentos da filosofia peirceana, notamos como o atendimento à saúde baseado nesses pressupostos seria guiado pelo método científico pragmático: a partir de uma gama de possibilidades de ações e reações exibidas pela singularidade dos fenômenos observados, na formulação de hipóteses comunicadas entre pares e com o público diretamente interessado e a dedução de consequências lógicas expressas no planejamento da terapêutica que se manteria, porém, aberta a revisões, suspensões e retomadas de acordo com a experiência observada.

Esse processo potencialmente contínuo é chamado por Peirce de semiose, ou ação do signo, e sua semiótica é uma tentativa de expor os componentes fundamentais das relações lógicas envolvidas nos processos de percepção, representação e comunicação (PEIRCE, 1992). 


\section{0 processo de comunicação como semiose}

O processo de comunicação, na visão da semiótica peirceana, é baseado numa relação lógica entre três aspectos básicos: (S-O-I) Signo, Objeto e Interpretante (PEIRCE, 1992). Signo é tudo aquilo que representa algo de forma a criar um efeito qualquer. Aquilo que é representado pelo signo é o seu Objeto e o possível efeito produzido é o seu Interpretante (ROMANINI, 2006). Se o signo representa seu objeto por meio de uma imagem ou semelhança, é um ícone (como uma radiografia, por exemplo). Se representa seu objeto por uma conexão física, concreta, é um índice (como a febre expressa num termômetro ou um índice de glicose expresso num exame). Se o signo representa seu objeto por meio de convenções ou hábitos naturais, é um símbolo (como as palavras escritas na bula de um medicamento, descrevendo a posologia).

A representação que o signo faz de seu objeto não é mecanicamente determinada, mas falível e baseada em processos hipotéticos dinâmicos, em contínua transformação. Da mesma forma, a interpretação ou efeito produzido pela representação não é produzida automaticamente, mas sujeita a um contexto interpretativo que é sempre irrepetível em suas dimensões qualitativas. 0 que se apresenta como ícone num contexto e situação pode ser considerado um índice ou símbolo noutros. Uma dor na virilha pode ser apenas um índice de algo que está errado para o paciente leigo, mas pode ser um símbolo óbvio de apendicite para um médico competente e experiente. As três doutrinas da filosofia peirceana expostas acima são necessárias para entendimento da semiose como um processo comunicativo dinâmico, relacional, criativo e teleológico, ou seja, que participa de um propósito maior que emerge naturalmente na comunidade onde a semiose acontece. 
O signo não é um a priori. Nada é signo por definição, mas qualquer coisa pode se tornar um signo se for colocada numa relação triádica da forma descrita acima. De fato, o dinamismo da tríade sígnica possibilita que o que é considerado Signo em um dado momento e situação pode ser o Objeto de um novo Signo subsequente, e é justamente nesse movimento que se produz o processo de comunicação.

Para entender a semiótica como lógica dos processos dinâmicos de comunicação, é preciso ir além dos três aspectos básicos apresentados acima. Na fase madura de suas pesquisas, a partir de 1900, Peirce chegou à conclusão de que o aspecto do objeto deveria ser dividido em dois, a que chamou de objeto dinâmico e objeto imediato. Isso porque um signo não consegue representar todas as propriedades do objeto, mas precisa selecionar uma, ou algumas delas, e apresentá-la na forma de uma ideia, a que Peirce deu o nome de Objeto Imediato. Além disso, o aspecto do interpretante deve ser dividido em três aspectos:

1) A interpretabilidade implícita do signo, ou o conjunto das possibilidades interpretativas que um signo carrega consigo, antes mesmo de ser efetivamente interpretado. A esse aspecto Peirce deu o nome de Interpretante Imediato.

2) 0 interpretante efetivamente produzido pelo signo, que atualiza uma das possibilidades interpretativas do interpretante imediato e se apresenta espaço-temporalmente definido. A esse aspecto Peirce deu o nome de Interpretante Dinâmico.

3) 0 interpretante que o signo estaria destinado a produzir se atingisse todos os propósitos virtualmente possíveis, ou a maneira como o signo se reproduziria na mente do intérprete se o processo de semiose tivesse uma performance ideal. Peirce o chamou de Interpretante Final. 


\section{Um choro pode comunicar muito}

Vamos a um exemplo simples, mas que nos permite entender melhor a utilidade da semiótica peirceana para o cuidado e a saúde humana. 0 primeiro som que enviamos ao mundo ao nascermos é, quase sempre, um choro. Este som é um signo repleto de significados. É um signo porque foi selecionado na evolução de nossa espécie por uma razão importante: ajudar na comunicação entre pais e bebê no longo período de imaturidade que se segue ao nascimento da criança. O ser humano é o primata que leva mais tempo para atingir a maturidade adulta. Por um longo e delicado período, quando a vida do bebê está nas mãos dos pais, comportamentos como o choro e o riso são signos importantes para que o bebê comunique aos pais seu desconforto ou satisfação. 0 choro é um signo que possui, portanto, um interpretante imediato e um objeto imediato, definidos atavicamente no nível da espécie humana.

Essa interpretabilidade fundamentada, feita de interpretantes imediatos e objetos imediatos, confere ao signochoro a potencialidade de produzir interpretantes dinâmicos na mãe da criança. De fato, se a mãe vê seu filho chorar, o "instinto" (ou hábito ou hipótese de interpretação) materno a faz especular sobre o motivo do desconforto de seu filho e em maneiras de aliviar seu sofrimento. Semioticamente, portanto, o choro é um signo, a razão ou causa do choro (fome? dor?) é seu objeto dinâmico. A ideia, falível e sujeita a alterações, criada na mente da mãe de forma a representar o objeto dinâmico é o objeto imediato do signo-choro. As atitudes que ela toma tentando interpretar corretamente esse signo são seus interpretantes dinâmicos. 0 interpretante final do signo é a atitude que a mãe deveria tomar para fazer com que seu bebê 
deixasse de sentir o desconforto e que ela deixasse de sentir a aflição instintiva que sente ao ver seu bebê chorando. É o retorno a um estado de tranquilidade.

0 bebê só vai parar de chorar quando o objeto imediato produzido na mente da mãe se conformar com o objeto dinâmico. Numa primeira tentativa, a mãe dá o seio pensando que ele sente fome, mas o bebê ainda chora. 0 ato de dar o seio é um interpretante dinâmico que atualiza um possível interpretante imediato. Afinal, faz parte da interpretabilidade do signo "choro", selecionada evolutivamente, que a criança possa estar com fome. A mãe então verifica a fralda (um outro interpretante dinâmico que atualiza uma outra possibilidade), mas o bebê ainda chora. Noutra tentativa ainda, massageia a barriga da criança, que finalmente para de chorar.

0 choro era provocado por gases. Nesse momento, o objeto imediato produzido pela mãe (expresso na ideia hipotética "talvez sejam gases") conformou-se ao objeto dinâmico real do signo "choro" (a dor real causada na criança pelos gases), gerando um interpretante dinâmico (a massagem na barriguinha) que, por sua vez, criou um interpretante final: o retorno do bebê e da mãe a um estado de comunhão tranquila e feliz, que é uma resultante estética e sentimental da lógica comunicativa da vida.

\section{O cuidar profissional não é diferente}

0 grito ou choro de uma mulher no momento de parir também são Signos que representam seu Objeto (o sentimento de dor, angústia, desespero, fragilidade que faz a mulher chorar nessa situação). No entanto, a comunicação, via de regra, se faz de maneira descontextualizada, pois o que a mulher representa por meio do choro (o seu sofrimento), é 'rebatido' 
por um procedimento técnico-científico apriorístico, que comumente é realizado de maneira fria, submetido ao peso do código legal que rege cada profissão e também aos protocolos pré-determinados no âmbito da racionalidade técnica.

Parece haver uma condicionante no processo de comunicação do profissional de saúde com a pessoa assistida. Essa condicionante diz respeito ao campo estreito de possíveis interpretações, por parte desse profissional, frente às diversas possibilidades de linguagem que a pessoa assistida poderia ter. Entendemos linguagem como um pensar de maneira organizada com base na compreensão dos diversos fenômenos percebidos no mundo (SANTOS, 2011). Caberia ao profissional de saúde demonstrar uma interpretabilidade generosa e aberta à experiência genuína que só é possível a partir da percepção, procurar criar ideias representativas (objetos imediatos) que compreendam a causa do choro como uma expressão de um sofrimento genuíno. Reprimir o choro seria desconsiderar o Signo, ou seja, eliminar o sentido que ele oferece como possibilidade interpretativa; seria também impedir a busca por interpretantes dinâmicos congruentes (ações concretas, procedimentos, uma palavra de conforto, um carinho) e que permitam a elaboração de um interpretante final que conduza ao apaziguamento do sofrimento.

A comunicação entre profissional de saúde e mulher assistida deveria suprir essa deficiência (a "humanização do atendimento"), mas o paradigma atual não abre espaço para uma comunicação agapista (amorosa), falibilista (sem prepotência) e tiquista (aberta ao acaso que surge na irrepetibilidade das situações concretas), como defendeu Peirce. 


\section{Os tipos de raciocínio envolvidos}

A semiose de processos investigativos e baseados na necessidade de uma conduta inteligente envolve formas de juízos lógicos que permitem balizar as etapas dos procedimentos. Peirce (1992) defende que há três tipos de raciocínio envolvidos no método genuinamente científico: abdução, dedução e indução.

O raciocínio abdutivo apresenta fatos em suas premissas; estas mostram similaridade com o fato enunciado na conclusão, ou seja, o raciocínio abdutivo trabalha associando ideias por similaridade; são hipóteses abstratas que podem ser verdadeiras ou não. Por exemplo: se um membro de uma família é diagnosticado com uma enfermidade contagiosa e, passados alguns dias, um outro membro apresenta sintomas semelhantes, o raciocínio abdutivo nos permite inferir a hipótese provável de que tem a mesma enfermidade de seu parente.

O raciocínio dedutivo é intermediário entre o abdutivo e o indutivo. Na dedução partimos de um estado de coisas hipotético, construído abdutivamente, para dele extrair as consequências necessárias. Peirce insistiu que todo raciocínio dedutivo é diagramático: o investigador constrói em sua mente um diagrama mental relacionando os fatos observados numa totalidade hipotética que se apresenta como uma imagem icônica. A dedução simplesmente segue as consequências necessárias da adoção de uma hipótese, sem valorar se é correta ou não. Seguindo no mesmo exemplo apresentado acima, a dedução permite que o profissional de saúde extraia as consequências necessárias da hipótese de que a mesma doença aflige o segundo membro da família, iniciando o tratamento necessário para combatê-la. 
0 raciocínio indutivo é essencialmente experimental; ele "requer que se observe a experiência" realizada a partir das ações definidas dedutivamente, para verificar se a hipótese adotada condiz com a realidade. Ainda no exemplo que vimos usando, o experimento consiste em ministrar os procedimentos recomendados pela dedução e observar os resultados. Se o paciente apresentar melhora de acordo com o previsto pela adoção das medidas necessárias, terá havido a confirmação da hipótese inicial. Ou seja, a indução testa o resultado das consequências formuladas dedutivamente.

Assim, podemos dizer que quanto mais amplo e renovável for o raciocínio abdutivo por meio da diversidade de interpretantes imediatos, maiores serão as possibilidades de ampliação do diagrama traçado pelo raciocínio dedutivo e, sendo assim, maiores possibilidades terão de representação nas diversas circunstâncias do mundo real.

Retomando a pesquisa realizada por Caron e Silva (2002), podemos dizer que, sob a ótica da semiótica, o processo de comunicação estabelecido entre os profissionais de saúde e a mulher se faz em um campo limitado. Ou seja, o profissional da saúde parece operar por meio do raciocínio dedutivo e indutivo guiado pelo peso das leis, do método científico, das legislações que regem o exercício profissional. Sendo assim, o raciocínio abdutivo, que é rico em contribuições inovadoras e diversificadas, atua em um campo estreito; o diagrama é reduzido e as possibilidades de experimentação também são estreitadas, ou seja, a possibilidade de comunicação entre o profissional de saúde e a mulher assistida parece limitada ao método cartesiano de fazer ciência, que concebe a realidade acabada, definida pela verdade transformada em fatos. 


\section{As origens do pensamento semiótico e sua relação com a medicina}

A relação da semiótica com a área da saúde é ancestral. Ginzburg (2008), por exemplo, faz uma análise aprofundada da narrativa dos caçadores das comunidades primitivas e dos textos adivinhatórios mesopotâmicos que datam de pelo menos 3000 a. C., para explicar a relação desses com o diagnóstico e o prognóstico da medicina. Para ele, o modelo investigatório de interpretação de pistas e o modelo adivinhatório utilizado pelos adoradores dos deuses mesopotâmicos têm semelhança. A semelhança está no fato de ambos requererem exame detalhado do real, mesmo que este real seja corriqueiro, para facilitar o desvendamento dos fenômenos que o observador não poderia experimentar diretamente.

A adivinhação deu origem à escrita primitiva por meio da capacidade de abstração do ser humano. A diferença entre a adivinhação e a interpretação de rastros está no fato de a primeira apontar para possibilidades futuras e a segunda para um passado, ainda que recente. 0 caçador se amparava na experiência para narrar os rastros: "O caçador pode ter sido o primeiro a 'contar uma história' porque apenas caçadores sabiam como interpretar uma sequência coerente de eventos a partir de obscuros (e quase imperceptíveis) sinais deixados pela presa." (GINZBURG, 2008, p. 100).

Tanto o modelo investigatório dos caçadores quanto o dos textos mesopotâmicos eram orientados por fatos do presente, do real; sendo que o primeiro, de narrar a história com base em rastros, era garantido pela preservação da memória, da experiência do caçador em saber distinguir os rastros, as penas, as peles de animais e comparar com o achado do presente; enquanto o segundo modelo, adivinhatório, orientava- 
se pelo presente para apontar o futuro. Desses modelos emergiram, posteriormente, várias áreas de conhecimentos, uma delas é a médica. Com base nesses dois modelos a ciência médica, da Grécia Antiga, orientava a elaboração do diagnóstico explicando o passado, o presente e o prognóstico.

A medicina da Grécia Antiga colocou em evidência o corpo, a fala e a história como objetos de investigação sem, contudo, considerar os aspectos adivinhatórios de intervenção divina. Para essa medicina, o tratamento era escolhido com base na observação e registros cuidadosos de cada sintoma e a partir desses registros as histórias de cada doença eram construídas. Essa atitude indicava de um lado, a natureza infalível do método adivinhatório e do outro a natureza provisória, conjectural do conhecimento humano. Os médicos, as mulheres, os historiadores, os políticos, os marinheiros, dentre outros, eram considerados possuidores desse saber conjectural (GINZBURG, 2008).

Anterior ao século XVII o saber da medicina era concebido como arte ou vocação e o exercício desta profissão era realizado na residência do enfermo, por meio da observação clínica direta a esse; acreditava-se que a arte médica só se aprendia no seu exercício prático.

0 modelo experimental de fazer ciência na área médica ganhou peso no século XVII, na Europa, com os avanços das descobertas científicas, o florescimento do sistema capitalista, a necessidade de um corpo saudável para a força de trabalho, dentre outros fatores. A prática médica exigia rigor científico em suas análises eliminando os fenômenos que não fossem passíveis de serem mensurados, comprovados por meio da experimentação. Esta situação contribuiu para a legitimidade do saber médico, que amparado pela racionalidade técnica passou a exercer poder sobre o corpo do enfermo. Se- 
gundo Foucault (1992, p. 111) é nesse período que "o indivíduo emerge como objeto do saber e da prática médicos".

Podemos entender que houve um deslocamento do modelo de assistência médica e, consequentemente, da concepção de doente e doença. 0 contexto político, econômico, social e cultural da era moderna contribuiu para desconsiderar as explicações adivinhatórias dos fenômenos naturais e outros não explicáveis pela inteligência humana. As explicações dos fenômenos por meio da experimentação científica acabam por ressaltar o conhecimento técnico em detrimento de outros conhecimentos.

Kuhn (1998) ao analisar o estatuto epistemológico das ciências humanas afirma que o problema da cientificidade é considerar que os conhecimentos objetivos são produtos intelectuais, capazes de satisfazer a dois critérios inseparáveis: o primeiro é focado em explicar satisfatoriamente os fenômenos não inteligíveis ao ser humano e o segundo, de resistir às tentativas de falsificação sistemática e rigorosamente empreendidas. Sendo assim, as ciências humanas não teriam o status de ciência por não situar sua cientificidade em resultados exatos, matemáticos. As manifestações advindas das percepções sensíveis como chorar, gritar e outros sentimentos também seriam desconsideradas ou situadas em uma posição hierarquicamente inferior à capacidade intelectual do ser humano.

Alguns estudos como, por exemplo, os de Silva (2004; 2013) mostram que a utilização do método científico de maneira a ressaltar o conhecimento técnico científico suprimindo outros conhecimentos tem sido um complicador no atendimento à saúde. Tendo em vista que a ciência é também uma forma de linguagem, a ciência médica, e outras da área da saúde, ao amparar-se na racionalidade técnica como fundamentação única para suas práticas, costuma orientar-se por códigos 
frios, indecifráveis e burocráticos para elaborar e constatar seus diagnósticos e tratamentos. Esta situação contribui para uma comunicação descontextualizada no atendimento à saúde gerando uma assistência desumanizada.

Acreditamos que a formação do profissional de saúde poderia possibilitar a utilização do método científico compreendendo os fenômenos em sua totalidade; a semiótica por meio da semiose poderia oferecer esta compreensão, que favoreceria concepções articuladas, por exemplo, manifestações subjetivas-objetivas; normal-patológico, teoria-prática, dentre outras que permanecem, através dos séculos, desarticuladas e hierarquizadas na área da saúde.

\section{A contribuição da semiótica para a formação do profissional da área da saúde}

Muitas são as tentativas, por parte de docentes e de órgãos governamentais, de formar profissionais sensíveis, capazes de perceber e considerar os diferentes contextos das práticas; conscientes da fragilidade humana e a partir desta construir cuidadosamente seu plano de trabalho. Estas tentativas, na maioria das vezes, visam a possibilitar uma comunicação significativa para todos os agentes envolvidos no processo de reabilitação da pessoa assistida: o profissional de saúde, a pessoa que precisa de cuidados, sua família e outros. Estes esforços parecem esbarrar na supremacia dos aspectos biológicos e das intervenções técnico-científicas que ainda aparece muito forte na formação do profissional da área da saúde; esta situação torna os discursos agressivos, os planos de trabalho desconexos ao campo de significações da pessoa que requer cuidados.

Restrepo (1998, p. 86) afirma que não podemos ser in- 
diferentes à produção do discurso, uma vez que as palavras podem ser ternas; o discurso pode "agradar e comover" como também "agredir e violentar". Este autor analisa de maneira ampla o desafeto percebido atualmente nas relações humanas e diz que os maus-tratos e a intolerância que se propagam de maneira sutil, ou não, em nossas sociedades, no mundo contemporâneo, são porque não conseguimos conceitualizar ainda o importante papel da afetividade. Na ciência, isto se tornou evidente à medida que expulsamos a afetividade das atividades científicas. 0 mesmo autor afirma que o que nos diferencia da inteligência artificial é justamente a capacidade de nos emocionarmos. Entendemos que tal capacidade ao invés de ser sucumbida, como parece ser, diante da supremacia do saber técnico-científico, deveria ser explorada na formação do profissional da saúde.

A disciplina, os códigos que caracterizam a linguagem da área da saúde, o vestuário, a burocratização das atividades, a rotina dos procedimentos, os protocolos e manuais formam uma imagem de guerreiro que contribui para excluir a possibilidade de um discurso terno. Assim, o estudante da área da saúde à medida que recebe o certificado de sua formação -legitimando-se como profissional - e que faz o juramento como prescreve cada profissão nessa área parece vestir-se com uma armadura de guerreiro a qual lhe confere um poder de combate tanto dos micro-organismos, quanto dos seres humanos enfermos que dependem de um tratamento para reabilitação de sua saúde.

Apontamos a urgência de recorrer a uma formação do profissional da saúde que privilegie a estética como moduladora de sensibilidades e como tal requer que este profissional utilize todos os seus sentidos: olfato, visão, audição, tato, paladar, com delicadeza, para explorar as possibilidades exis- 
tentes em cada atendimento à pessoa que precisa de cuidados. Esta estética permitiria um acolhimento das diferenças, das ações e palavras ternas sem, contudo, desconsiderar as necessidades de realização de procedimentos.

\section{Pressupostos para a formação do profissional da área da saúde}

Sem deixar de considerar as peculiaridades de cada área que forma as ciências da saúde, propomos uma formação que possibilite a compreensão de como acontece o processo de significação e representação na mente humana, ou seja, de como ocorre o processo de comunicação. Para que, com base nesta compreensão, vários aspectos pudessem ser contemplados no atendimento à saúde: o profissional poderia se sensibilizar frente à diversidade humana no que diz respeito às possibilidades de significações e representações, que 'traduzem' os fenômenos que se apresentam no mundo; o profissional teria a consciência de aberturas para manifestações das sensibilidades no atendimento clínico; o profissional utilizaria o conhecimento técnico-científico de maneira a acomodá-lo a outros tipos de conhecimentos, uma vez que haveria a diluição do poder que este traz ao profissional da saúde sobre o enfermo ou a pessoa que requer cuidados.

A formação do profissional da saúde teria como base a compreensão da semiose como movimento sígnico que justifica a integração do corpo-mente e todas as manifestações subjetivas e objetivas dos seres vivos. Esse ensino teria como meta formar um profissional que "lançaria mão" de suas experiências de vida, de profissão 'desenhada' pelo raciocínio abdutivo para criar e desenvolver um diagrama da situação com a qual se depara. Este diagrama seria amplo o quanto possível 
para permitir a exploração das possibilidades lógicas necessárias e, por meio do raciocínio indutivo, das experiências que confrontem as possibilidades com o real. Quanto mais amplo o raciocínio abdutivo, mais possibilidades de os cenários das práticas serem acomodados. Assim, quanto mais amplo o interpretante e objeto imediato de nossas representações, mais condições de diagramarmos, formarmos hipóteses mais adequadas antes de submetê-las ao método técnico-científico.

0 que queremos dizer é que antes de definirmos uma terapêutica ou um plano de cuidados, poderíamos considerar a diversidade de possibilidades de interpretação dos fenômenos que a pessoa que requer cuidados poderia fazer; antes de respondermos às suas necessidades imediatamente com procedimentos técnicos e/ou medicamentosos. Isto não significa que não estamos de acordo com cuidados de urgência e emergência que requerem ações técnicas imediatas. Apontamos para condutas de rotina que se amparam tão somente em ações restritas ao uso de medicamentos e manobras técnicas, muitas vezes justificadas pela concepção fragmentada de microrganismo, doença e corpo. Diante desta realidade o que vemos é o aumento da falta de adesão ao tratamento médico e de enfermagem.

\section{Considerações finais}

O presente texto propõe utilizar o método científico pragmático de Peirce na formação do profissional da área da saúde. Compreendemos que esse método poderia ser explorado, dentre outros, na elaboração de um plano de cuidado/ tratamento. Respeitando as peculiaridades de cada área da saúde, o plano de cuidado/tratamento poderia ser concebido de natureza sígnica-diagramática, ou seja, poderia ser concebido como um processo projetivo pautado em um raciocínio 
lógico-dedutivo-diagramático.

Os fenômenos seriam percebidos em sua totalidade e seriam acolhidas as diversas possibilidades de representações destes. Por exemplo, uma doença (objeto do representamen) poderia ser interpretada do ponto de vista fisiopatológico, do ponto de vista das evidências de trabalhos científicos estatisticamente considerados, mas as interpretações não se esgotariam aí, abarcariam também um amplo espectro de possibilidades que poderia ser desenhado hipoteticamente com a ajuda de diversos subsídios, por exemplo, as concepções do enfermo a respeito de saúde, doença, corpo, dentre outros; da história de vida do enfermo-família que requer na formação do profissional da área da saúde. Compreendemos que esse método poderia ser explorado, dentre outros, na elaboração de um plano de cuidado/tratamento. Respeitando as peculiaridades de cada área da saúde, o plano de cuidado/tratamento poderia ser concebido de natureza sígnica-diagramática, ou seja, poderia ser concebido como um processo projetivo pautado em um raciocínio lógico-dedutivo-diagramático.

Os fenômenos seriam percebidos em sua totalidade e seriam acolhidas as diversas possibilidades de representação destes. Por exemplo, uma doença (objeto do representamen) poderia ser interpretada do ponto de vista fisiopatológico, do ponto de vista das evidências de trabalhos científicos estatisticamente considerados, mas as interpretações não se esgotariam aí, abarcariam também um amplo espectro de possibilidades que poderia ser desenhado hipoteticamente com a ajuda de diversos subsídios como: as concepções do enfermo a respeito de saúde, doença, corpo, dentre outros; da história de vida do enfermo-família que requer cuidado-tratamento, da relação dessa história com o contexto sócio-econômico-político-cultural-religioso, dentre outros. 
Para tanto, o profissional de saúde se pautaria em concepções de organismo humano. Como um sistema aberto em constante interação e reação, capaz de se auto-organizar. Adotamos aqui a definição de sistema como "uma entidade constituída por uma coleção de objetos que mantém relações entre si e com objetos de seu meio ambiente, e que possui identidade e um conjunto de características." (BRESCIANI; OTTAVIANO, 2004, p.04).

0 plano de cuidado/tratamento seria o resultado de um processo criativo do profissional de saúde; esse plano seria uma modelagem rica de possibilidades, que contemplaria as concepções do enfermo-família, os aspectos fisiopatológicos, as evidências científicas, os procedimentos técnico-científicos e que permitiria 'folgas' para o auto-cuidado, a auto-organização.

A elaboração do plano de cuidado/tratamento seria dinâmica; cada signo interpretante se tornaria objeto para representar uma nova relação tríadica (S-O-I); então o caso/ doença que seria objeto em uma relação, poderia dinamicamente ser interpretante em outra possibilidade de relação, ou seja: no processo de comunicação entre o profissional da área da saúde e a pessoa assistida, o que seria objeto para um poderia ser interpretante para outro. À medida que a execução do plano se desenvolvesse, a relação dos diagramas com o problema iria se aprofundando e as diversas possibilidades de representações esboçadas iriam ganhando forma.

Cada diagrama seria uma possibilidade de cuidado/tratamento para resolver o problema. Segundo esta ótica, a elaboração diagramática do cuidado/tratamento não se restringiria apenas ao olhar técnico científico do profissional da área da saúde, mas seria uma elaboração modelada também pelo enfermo-família, permitindo a autonomia deste para tratar/ cuidar do seu próprio corpo. 


\section{REFERÊNCIAS}

\section{BERGMAN, M. Reflections on the Role of the Communicative} Sign in Semeiotic. In: TRANSACTIONS OF THE CHARLES S. PEIRCE SOCIETY, v. 36, n. 2, p. 225-254, 2000. Disponível em: <http://www.helsinki.fi/science/commens/papers/refrole. html >. Acesso em: 10 fev. 2015.

BRASIL. Secretaria de Políticas de Saúde. Política Nacional de Humanização da atenção e gestão no Sistema Único de Saúde - Humaniza SUS. Brasília: Ministério da Saúde; 2004.

- Secretaria de Políticas de Saúde. Área Técnica de Saúde da Mulher. Parto, aborto e puerpério: assistência humanizada à mulher. Brasília: Ministério da Saúde; 2001.

. Secretaria Geral do Ministério da Saúde. VIII Conferência Nacional de Saúde. Brasília: Ministério da Saúde; 1986.

BRESCIANI, E.; D’OTTAVIANO, Í.M.L. Auto-organização e Criação. Revista Multidisciplinar dos Centros e Núcleos da Universidade Estadual de Campinas, Campinas, v.3, n.10, p.04-10, 2004.

CARON, O. A. F.; SILVA, I. A. Parturiente e equipe obstétrica: a difícil arte da comunicação, Revista Latino Americana de Enfermagem, Ribeirão Preto, v. 10, n. 4, p. 72-81, 2002.

FOUCALT, M. Microfísica do Poder. Rio de Janeiro: Graal, 1992.

GINZBURG, C. Chaves do Mistério. In: ECO, U.; SEBEOK, T. A. (Org.). $O$ signo de três. São Paulo: Perspectiva; 2008. p. 100103.

KUHN, T. A estrutura das revoluções científicas. São Paulo: Perspectiva, 1998. 
MANETTI, G. Theories of the Sign in Classical Antiquity. Bloomington: Indiana University Press, 1993.

PEIRCE, C. S. Collected Papers (Vols. I a VIII). Charlotterville: Intelex Co.; Cambridge: Harvard Univ. Press, 1992.

RESTREPO, L. C. O Direito à ternura. Petrópolis: Vozes, 1998. ROMANINI, V. Semiótica minuta: especulações sobre a gramática dos signos a partir da obra de Charles S. Peirce. 2006. 250 f. Tese (Doutorado em Comunicação) - Escola de Comunicação e Artes, Universidade de São Paulo, São Paulo, 2006.

SANTOS, F. A. Transversalidade/Design/Linguagens. Revista Tríade, Sorocaba, São Paulo, 2011. Disponível em: <http:// revistatríades.com.br/2011>. Acesso em: 10 mar. 2013.

SILVA, E. A. A relação teoria-prática em um curso de pósgraduação (stricto sensu) em enfermagem. 2013. 260 f. Relatório (Pós-doutorado em Educação) - Faculdade de Educação, Universidade Estadual de Campinas, Campinas, 2013.

Análise sobre a formação do professor de graduação em enfermagem. 2004. 169 f. Tese (Doutorado em Educação) - Faculdade de Educação, Universidade de São Paulo, São Paulo, 2004.

Artigo recebido em setembro de 2014 e aprovado em dezembro de 2014.

Disponível em: http://seer.fclar.unesp.br/casa 